\title{
Trombose de veia central da retina bilateral associada à síndrome de hiperviscosidade sanguínea - Relato de caso
}

\author{
Bilateral central retinal vein occlusion associated with blood hyperviscosity syndrome- \\ Case report
}

John Helal Jr'

Fernando Korn Malerbi ${ }^{2}$

Roberto Melarag'no Filho ${ }^{3}$
Trabalho desenvolvido na Clínica Oftalmológica do Hospital das Clínicas da Faculdade de Medicina da Universidade de São Paulo.

${ }^{1}$ Médico Doutor - Assistente do Departamento de Oftalmologia do Hospital das Clínicas da Faculdade de Medicina da Universidade de São Paulo - USP.

${ }^{2}$ Médico Residente do Departamento de Oftalmologia do Hospital das Clínicas da Faculdade de Medicina da Universidade de São Paulo - USP.

(in memoriam) Professor Livre-Docente da Clínica Neurológica do Hospital das Clínicas da Faculdade de Medicina da Universidade de São Paulo - USP.

Cada autor declara que não possui interesse financeiro sob qualquer aspecto neste estudo.

Endereço para correspondência: Fernando Malerbi, Rua Jacques Félix, 314/51 - São Paulo (SP) - CEP 04509-001 E-mail: femalerbi@terra.com.br

Recebido para publicação em 04.02.2004 Versão revisada recebida em 14.06.2004 Aprovação em 25.08.2004

\begin{tabular}{|l|}
\hline RESUMO \\
\hline Relato de caso de um paciente masculino de 16 anos de idade com queixa \\
inicial de baixa da acuidade visual e que no exame oftalmológico foi \\
encontrado edema de papila bilateral, que evoluiu para trombose da veia \\
central da retina em ambos os olhos. Na investigação laboratorial, foi feito \\
diagnóstico de um mieloma múltiplo tipo IgA que cursava com síndrome \\
de hiperviscosidade sanguínea, o que explicava o quadro oftalmológico. \\
Após tratamento específico, o paciente apresentou melhora tanto da \\
acuidade visual quanto do aspecto fundoscópico. O achado de oclusão \\
de veia central da retina bilateral pode levar ao diagnóstico de importantes \\
doenças sistêmicas. Os achados fundoscópicos podem servir de parâmetro \\
na avaliação do tratamento.
\end{tabular}

Descritores: Oclusão da veia retiniana; Veia retiniana; Viscosidade sanguínea; Mieloma múltiplo; Relatos de casos [Tipo de publicação].

\section{INTRODUÇÃ̃O}

A síndrome de hiperviscosidade sanguínea é uma entidade associada, principalmente, a neoplasias malignas ${ }^{(1)}$. Ela também pode ocorrer em outras situações, como causas iatrogênicas ${ }^{(2)}$ - por exemplo administração de imunoglobulina endovenosa - e em outras doenças não neoplásicas, como por exemplo, a artrite reumatóide ${ }^{(1)}$. Esta síndrome é caracterizada por sangramentos de mucosas, geralmente na forma de epistaxe, retinopatia, alterações neurológicas e, por vezes, acometimento do sistema cardiovascular, com insuficiência cardíaca. Há diversos exames laboratoriais que auxiliam no diagnóstico, incluindo todos aqueles dirigidos à detecção da doença ou da malignidade de base. Entretanto, a alteração laboratorial mais típica da síndrome é o aumento da viscosidade sanguínea.

$\mathrm{O}$ tratamento da síndrome é dirigido à doença de base e composto também por medidas adjuvantes, como hidratação e plasmaférese, sendo que esta última constitui o tratamento de escolha, atualmente.

\section{RELATO DO CASO}

Um paciente masculino de 16 anos, branco, procurou atendimento médico com queixa de embaçamento visual, que piorava pela manhã, além de fraqueza. Ele relatava que, havia três meses, tinha apresentado quadro semelhante, acompanhado de epistaxe. Naquela ocasião, procurou outro 
serviço onde recebeu diagnóstico de "papiledema" e foi tratado com esteróides orais, apresentando melhora transitória dos sintomas.

Ao exame físico geral e neurológico, não havia alterações.

Ao exame oftalmológico, ele tinha acuidade visual de 20/40 no OD e 20/70 no OE; sem melhora com refração. À fundoscopia, evidenciava-se edema de papila bilateral, com veias engurgitadas e tortuosas; hemorragias retinianas em chama de vela no pólo posterior e na periferia (Figura 1).

$\mathrm{Na}$ angiofluoresceinografia observou-se atraso no enchimento e notou-se um extravasamento progressivo de contraste a partir de capilares do nervo óptico com ínicio na fase arterial (Figura 2).

A investigação laboratorial apontou para o diagnóstico de mieloma múltiplo. O paciente apresentou proteína de Bence Jones positiva na urina e mielograma que revelou plasmócitos imaturos com alterações nucleares típicas. A radiografia de crânio mostrava lesões líticas. A análise de imunoglobulinas por imunoeletroforese revelou que se tratava de mieloma múltiplo do tipo $\operatorname{Ig}$ A.

Além disso, o paciente apresentava importante anemia, com nível de hemoglobina de 7,9 mg/dL.

Com o diagnóstico de mieloma múltiplo IgA, o tratamento

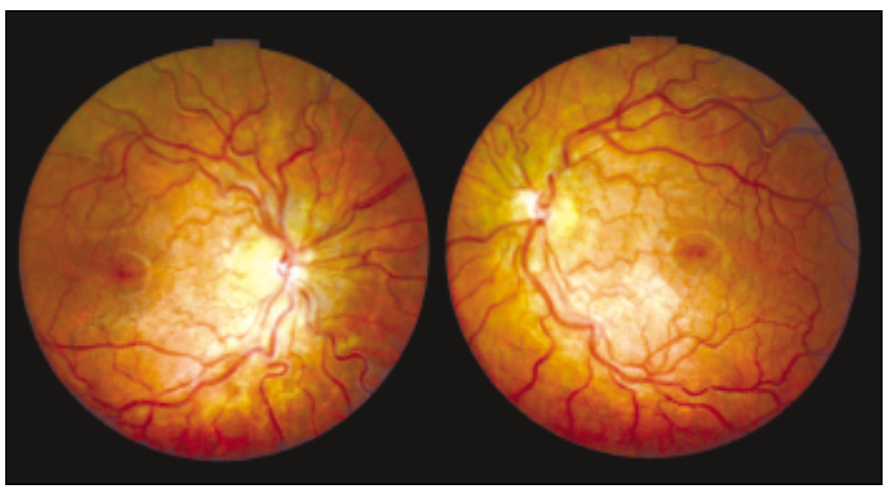

Figura 1 - Fundo de olho inicial. Podem-se observar bilateralmente: edema de papila, tortuosidade e engurgitamento venoso e hemorragias superficiais

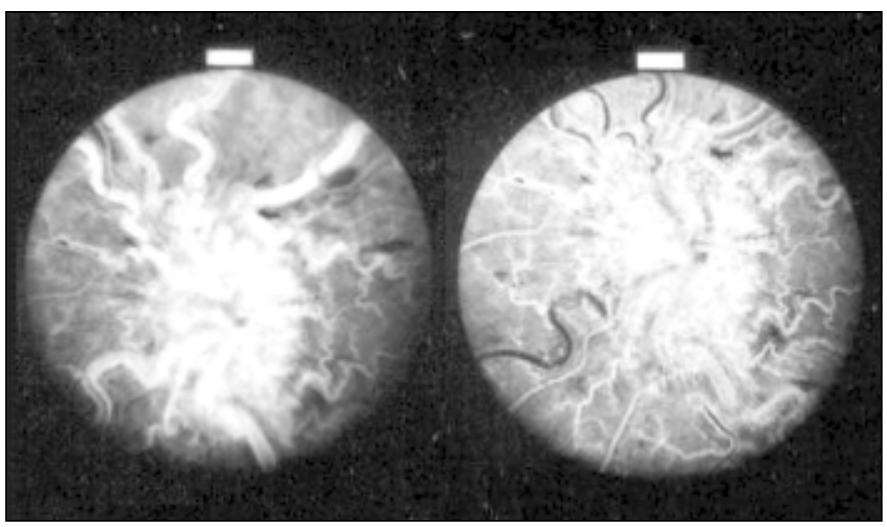

Figura 2 - Angiofluoresceinografia. Nota-se extravasamento de contraste a partir da papila bilateralmente foi iniciado com plasmaférese, anti-metabólito (Alkeran) e esteróides (Prednisona).

O paciente obteve melhora clínica e laboratorial, obtendo acuidade de 20/20 em AO. Houve regressão do edema de papila e normalização do aspecto fundoscópico, exceto pela presença de veias tortuosas e dilatadas.

\section{DISCUSSÃO}

Este trabalho relata um quadro que corresponde a uma apresentação do mieloma múltiplo em uma idade atípica, com um subtipo de imunoglobulina que não é o mais comum ( $\operatorname{Ig} \mathrm{A})$. Associado ao mieloma, o paciente apresentou uma síndrome de hiperviscosidade sanguínea que provocou as alterações retinianas descritas.

A síndrome de hiperviscosidade sanguínea pode estar associada, mais comumente, à macroglobulinemia de Waldenstrom $^{(3)}$, podendo também ocorrer mais raramente no mieloma múltiplo ${ }^{(4)}$, doença da cadeia leve kappa, crioglobulinemia e, raramente, na artrite reumatóide. Os sintomas ocorrem quando as imunoglobulinas, que se encontram aumentadas, interagem com outros elementos do sangue, tais como eritrócitos, plaquetas, ou outras globulinas, desta forma impedindo o fluxo normal. As imunoglobulinas são, na maioria das vezes, moléculas $\operatorname{IgM}$ e, em ocasiões mais raras, $\operatorname{IgA}$, como neste caso, e IgG3.

Os achados fundoscópicos descritos podem dever-se à estase do fluxo venoso, causada pelo aumento da viscosidade sanguínea ${ }^{(1)}$. Outra causa considerada é a anemia de doença crônica presente nestas doenças hematológicas, que provoca um grau de sofrimento no tecido retiniano que contribui para as alterações encontradas. $\mathrm{O}$ risco de pacientes com mieloma múltiplo desenvolverem retinopatia aumenta se houver anemia, com níveis de hemoglobina menores que $10 \mathrm{mg} / \mathrm{dL}^{(5)}$.

$\mathrm{O}$ aspecto descrito ("fundus paraproteinemicus") ${ }^{(1)}$ não é típico desta doença, sendo observado em diversas doenças hematológicas que cursam com alteração do fluxo sanguíneo ou hiperviscosidade devida a qualquer causa, como por exemplo a síndrome iatrogênica descrita por $\mathrm{Oh}^{(2)}$, em que um paciente submetido a altas doses de imunoglobulina endovenosa desenvolveu esta síndrome, com os achados fundoscópicos compatíveis.

Há relatos de casos na literatura de pacientes com mieloma múltiplo que desenvolveram alterações retinianas; porém, geralmente os pacientes correspondem a faixas etárias mais elevadas. Em uma revisão, foram encontrados casos de pacientes com idades que variavam entre 38 e $76 \operatorname{anos}^{(3,6-13)}$.

Em conclusão, este artigo mostra, através de um caso de apresentação atípica, a importância do oftalmologista no diagnóstico de graves doenças sistêmicas. $\mathrm{O}$ oftalmologista pode ser o primeiro médico procurado por pacientes com doenças que podem ter desfechos potencialmente devastadores; desta forma, deve contar com um alto nível de suspeição clínica e critérios judiciosos na investigação subseqüente. 


\section{ABSTRACT}

The authors report the case of a 16-year-old male patient who presented with blurred vision and bilateral optic disc edema, then developing bilateral central retinal vein occlusion. On laboratory work-up, he was found to have multiple myeloma IgA along with hyperviscosity syndrome, which led to the ophthalmological features. After proper treatment, the patient recovered visual acuity and normalized his eye fundus changes. Bilateral central retinal vein occlusion finding may yield the diagnosis of major systemic diseases. Fundoscopic features may serve as parameters on treatment evaluation.

Keywords: Retinal vein occlusion; Retinal vein; Blood viscosity; Multiple myeloma; Case reports [Publication type].

\section{REFERÊNCIAS}

1. Chiang CC, Begley S, Henderson SO. Central retinal vein occlusion due to hyperviscosity syndrome. J Emerg Med. 2000;18(1):23-6.
2. Oh KT, Boldt HC, Danis RP. Iatrogenic central retinal vein occlusion and hyperviscosity associated with high-dose intravenous immunoglobulin administration. Am J Ophthalmol. 1997;124(3):416-8.

3. Lindsley H, Teller D, Noonan B, Peterson M, Mannik M. Hyperviscosity syndrome in multiple myeloma. A reversible, concentration-dependent aggregation of the myeloma protein. Am J Med. 1973;54(5):682-8.

4. Knapp AJ, Gartner S, Henkind P. Multiple myeloma and its ocular manifestations. Surv Ophthalmol. 1987;31(5):343-51.

5. Holt JM, Gordon-Smith EC. Retinal abnormalities in diseases of the blood. $\mathrm{Br}$ J Ophthalmol. 1969;53(3):145-60.

6. Luxenberg MN, Mausolf FA. Retinal circulation in the hyperviscosity syndrome. Am J Ophthalmol. 1970;70(4):588-98.

7. Kopp WL, Beirne GJ, Burns RO. Hyperviscosity syndrome in multiple myeloma. Am J Med. 1967;43(1):141-6.

8. Carr RE, Henkind P. Retinal findings associated with serum hyperviscosity. Am J Ophthalmol. 1963;56:23-31.

9. Clarke E. Ophthalmological complications of multiple myelomatosis. Br J Ophthalmol. 1955;39(4):233-6.

10. Donnelly EJ. Ocular complications of multiple myelomatosis. Am J Ophthalmol. 1959;47(2):211-4.

11. Hayasaka S, Ugomori S, Kodama T, Noda S, Setogawa T. Central retinal vein occlusion in two patients with immunoglobulin $\mathrm{G}$ multiple myeloma associated with blood hyperviscosity. Ann Ophthalmol. 1993;25(5):191-4.

12. Brody JM, Butrus SI, Ashraf MF, Rabinowitz AI, Whitmore PV. Multiple myeloma presenting with bilateral exudative macular detachments. Acta Ophthalmol Scand. 1995;73(1):81-2.

13. Bronstein M. Ocular involvement in multiple myeloma. Arch Ophthal 1956; 55:188-192.

\section{CONGRESSO BRASILEIRO DE OFTALMOLOGIA}

\section{3 a 6 de Setembro de 2005 Centro de Convenções de Fortaleza - CE}

IN FO RMAÇÕ ES: Secretaria Executiva: Arx Produções \& Eventos Rua Júlio Siqueira, 970 - Dionísio Torres

60130-090 - Fortaleza (CE)

Fone: (85) 4011-1572 - Fax: 4011-1573

Email: cb02005@arxweb.com.br

Home-page: www.cb02005.com.br 